Article

\title{
Community of Inquiry on Facebook in a Formal Learning Setting in Higher Education
}

\author{
Masood Nazir ${ }^{1}$ and Natasa Brouwer ${ }^{2, *}$ \\ 1 University of Amsterdam, Weesperzijde 190, 1097 DZ Amsterdam, The Netherlands; M.Nazir@uva.nl \\ 2 Faculty of Science, University of Amsterdam, P.O. Box 94214, 1090 GE Amsterdam, The Netherlands \\ * Correspondence: natasa.brouwer@uva.nl; Tel.: +31-020-525-7986
}

Received: 11 November 2018; Accepted: 28 December 2018; Published: 7 January 2019

\begin{abstract}
This study demonstrates an application of Facebook for higher education in science (STEM), and it clarifies its impact on students' learning in a formal online learning setting. A combined qualitative and quantitative approach was used. Messages posted on Facebook were classified by qualitative transcript analysis. The perception and experience of students with Facebook were recorded by means of pre- and post-tests, using a treatment/control group approach. The results show that an integral Community of Inquiry (CoI) was formed on Facebook within the regular online course, encompassing all relevant $\mathrm{CoI}$ interactions leading to a powerful educational experience. Additionally, a type of CoI interaction "student-community" is observed, which was not reported before. The results show that the use of Facebook had positive effects on students' learning, only when the activities on Facebook were constructively integrated in a course design, and a moderator was present. More research is needed to include larger group sizes and other course designs.
\end{abstract}

Keywords: higher education; online learning; Community of Inquiry; social networks; transcript analysis; students' perception

\section{Introduction}

Rapid developments in networking technologies enable unlimited online communication, collaboration and teamwork. Recent research on social media and networking has addressed social interaction, and has showed that it has an important role in any learning process [1-4]. Aydin [5] has published an extensive review on the use of Facebook as an education environment. Doleck and Lajoie [4] have shown that the use of social media can affect academic performance. Still, much is to be learned about the application of social media in regular online courses in higher education.

The aim of the present research is to obtain more insight into the context and conditions in which learning on Facebook occurs, in regular online courses in higher education and about the impact it has on students.

\subsection{Learning Communities}

In their comprehensive literature review study Freeman et al. [6] argued that poorly effective traditional lecturing in higher education should be abandoned in favor of the active learning approach that fosters students' performance. Recently, Chiu \& Cheng [7] and Chen [8] showed that students' creativity and innovation capabilities are stimulated by an active learning approach. For effective learning experiences in online settings, the engagement of students is indispensable. Rapid development in networking technologies influenced the way we communicate and collaborate, and how we learn. Garrison, Anderson and Archer [9] established a framework of a Community of Inquiry (CoI) for a successful online learning experience in higher education. They have defined three presences as prerequisites to form a community in which students can effectively learn online: cognitive, 
teaching, and social presence [10-12]. In 2006, they introduced a qualitative transcript analysis as a method for evaluating the core elements of a Community of Inquiry [13]. The CoI framework was empirically verified by Arbaugh [14], and it is widely adopted now [15]. Arbaugh et al. [16] developed an instrument to measure CoI, a 34-item Likert-type questionnaire to quantitatively analyze the three core components of the CoI. The instrument was validated by using a multi-institutional sample. It is recognized as a stable instrument for the measurement of CoI $[17,18]$.

In an extensive literature study, Resta and Laferrière [19] discussed how computer-mediated networks support social interaction, cooperation, and collaborative learning that are needed for knowledge construction, and they gave a series of recommendations regarding the research in this field. Harasim [20] argued that a new theory of learning based on constructivism is needed, in order to fit the changes induced by technological development in the 21st century: the Online Collaborative Learning (OCL) theory. Different studies have shown positive effects of collaborative learning on the development of critical thinking [21,22]. Szeto [23] proposed to use CoI as an instructional approach in blended synchronous learning. Chen et al., [8] developed protocols as a strategy for effective communication in a community of inquiry. Szeto [23] showed that in an engineering course, the leadership role of the moderator increased the teaching presence to become more important than the social and cognitive presences.

\subsection{Social Networking Sites in Higher Education}

Social media have become an indispensable part of our personal and social life. Klamma et al. [24] discussed the opportunities of the social networking sites to support collaborative learning in lifelong learning. There is a growth in the popularity of social networking sites such as Facebook among the education community, students, and teachers, on- and off-campus [25]. Many universities engage with their students via Facebook, in order to increase the interaction between the faculty and its students [26]. McCarthy et al. [27] have revealed the advantages and disadvantages of using social media in higher education in order to enhance learning in blended learning settings. Based on the perceptions of students of four courses, Irwin et al. [28] concluded that Facebook could be an appropriate learning tool. Although only $51 \%$ of participants in these courses found Facebook effective, a large majority of $76 \%$ recommended the use of Facebook in future courses. Similarly, Sanchez et al. [29] found that Facebook has the potential for supporting collaborative learning, and recognized the social relation factors when using it in education. Sharma et al. [30] analyzed the factors that might motivate students to use social networking sites. They explained the educational usage of Facebook by linear and nonlinear modelling, and validate the model developed by Mazman and Usluel [31] in it. On the other hand, in an extensive review study Hew [32] has suggested that social networking sites, Facebook in particular, have less educational potential, and are mainly valuable for socialization. A large survey among the academic staff in Italy also showed ambivalence in scholars' views about the use of social media in higher education: lecturers see more obstacles than advantages in it [3].

With this research, we contribute to obtaining more insight into the capacity of social networking sites, Facebook in particular, in a formal learning setting in higher education. We aim to provide more insight about students' perception of using Facebook in addition to a learning management system such as Blackboard, which is related to their learning experience, grades, and overall learning satisfaction, from the perspective of $\mathrm{CoI}$ framework. This study aims to define the conditions that are required for a $\mathrm{CoI}$ to be formed and to be sustainable on Facebook in a formal learning setting, and to map the types of the activities in terms of CoI.

The following sub-questions are addressed in this study:

Q1. What types of interactions take place on Facebook within an educational group, which have an impact on student educational experience?

Q2. How does the use of Facebook during an online course impact students' perceptions of using Facebook for general educational purposes?

Q3. What effects does the use of Facebook have on students' perceptions regarding their grades? 
Q4. How does the use of Facebook for teaching and learning in a course influence students' perceptions regarding the elements of the Community of Inquiry?

Q5. How do students' opinions and experience regarding the three presences of the Community of Inquiry differ between the students who use Facebook during their course, and those who do not?

\section{Materials and Methods}

Multiple data sources were used, and a twofold methodology approach was applied, to achieve a broader understanding of the effects of the use of Facebook in higher education:

(a) A qualitative analysis of students' and moderators' messages posted on Facebook, using transcript analysis technique [13];

(b) A pre- and post-test analysis to evaluate the community of inquiry using validated CoI instruments [16].

The faculty ethical committee has given its approval for this research. A pre- and post-test questionnaire included informed consent. The students were informed about this research and the use of Facebook by the lecturer and by the researchers, via e-mails, before the start of the course. None of the students expressed any objection to this research in any sense. The demographics and other personal data that were used in the research were collected exclusively via the questionnaires that included informed consent. The qualitative data were first exported strictly anonymously to be further used in the research. The use of Facebook in all courses was optional and strictly voluntary. The students did not get any credit points for using Facebook, nor for the activities done in Facebook. In the course with the treatment group, there were also other different means to get information and support from the moderator (Blackboard platform with its tools, e-mail, and a weekly videoconferencing session in which students received explanations and could ask questions).

\subsection{Study Setting, Intervention, and Participants}

In this study six online courses of the Pre-Master Information Studies programme at the University of Amsterdam, the Netherlands were studied. The programme is organized for candidates who have knowledge deficiencies to be admitted to the Master Information Studies at the University of Amsterdam. The study was conducted in May-July 2017, when all six courses were given in parallel: ICT in Organizations, Data Mining, Business Studies, Knowledge Web, Programming for Data Science, and Academic Skills.

The participants of this study were 74 students who attended one or two of these six online courses. The students were between 20 and 34 years old, and the ratio of male:female was 70:30. The participants were located in different countries across the globe. The majority of students was from different parts of the Netherlands. In this research, the students in the Academic Skills course were chosen as a treatment group $(\mathrm{N}=38)$, and the students in other courses all together were chosen as a control group $(\mathrm{N}=36)$.

\subsubsection{Course Design}

The six courses of the Pre-Master Information Studies programme included in this study are designed to be interactive online courses that are eight weeks long. Each course takes the participants between $70-150 \mathrm{~h}$ to complete, depending on their pre-knowledge. The courses are fully delivered online, including the final exam. The course materials in the electronic learning environment, Blackboard, include reading, video, quizzes, and assignments. Asynchronous and synchronous communication are available in each course, for which Blackboard, Webex, and Facebook can be used. Each course has one online moderator who moderates the course, supports students in learning, and organizes weekly online videoconferencing meetings. 


\subsubsection{Intervention}

In the first three years of the Pre-Master Information Studies programme, from 2012 to 2015, all courses had used one common open Facebook page: "UvA Online Pre-Master Information Studies", with a goal to serve as a platform for less formal/social connections between the students who participated in the Pre-Master programme. The open Facebook page was set up to make it possible for students to use it without any support or intervention by the staff. Students (in total about 100 per year) could reach this Facebook page from each pre-master Blackboard course site, by following the link in the left menu of the course site. The use of the Facebook site was optional, and it was left up to the students as to what to do with it. The moderator paid no attention to it during the course. In 2015, the moderator of the course "Academic Skills" replaced this Facebook link in the Blackboard course site with a link to a Facebook closed group "Academic Skills UvA" (the treatment group of this study). In the rest of the courses, the situation remained the same (the control group of this study). The moderator of the course Academic Skills used this Facebook page in this pre-master course as a discussion forum (asynchronous communication). Visiting this Facebook site or attending the discussions during the course was optional, and no credit points were given for participation.

\subsection{Qualitative Analysis of Facebook Activity}

To define the types of interaction on Facebook, and to answer sub-question Q1, posts by students and by moderators were extracted. The type of posts was text. The exploratory qualitative research technique was used [13], based on the coding scheme of the Community of Inquiry [33] for studying asynchronous online education dialog. The coding was done by the first author in collaboration with the second author. In this collaboration, first, the procedure of coding was agreed with by both authors, by using other data sets that were not used in this research, for the purpose of becoming acquainted with the CoI coding. Next, any disagreements in coding were first discussed, and were solved before using it. The authors also discussed about the coding with one peer-researcher. The posts were coded and mapped out. The content analysis was divided into two sections: (1) Facebook open page "UvA Online Pre-Master Information Studies" (control group, 36 students), and (2) Facebook closed group "Academic Skills UvA" (treatment group, 38 students).

As the unit of analysis for coding in this study, any message posted by a single person on the course Facebook page or Facebook group was chosen. For the monitoring of the activities, and to download the posts and comments, an online Facebook Groups Analytics and Management tool "Grytics", was used [34]. As this tool is not used specifically in higher education, it has only been used for general analysis. For coding purposes, the data was downloaded and coded manually, and in the second step, the data obtained was analyzed with Microsoft Excel.

To set up the coding scheme and procedures, the data of the previous edition of the Pre-Master courses were collected. First, the interactions were extracted from the data by using the modes of interaction scheme $[33,35]$. Second, the data were coded by using the coding scheme of CoI for transcript analysis [13]. These data were only used for comparison and were not used further for the interpretation of the results in this study. The coding procedure was executed on the participant-generated data (text) in the ongoing online pre-master courses included in this study. During the active period of eight weeks, a researcher procured the role of an online ethnographer [36], and observed all participants' interactions on Facebook by becoming a member of their course Facebook page and Facebook group. The researcher passively observed the process, and did not engage with the participants on Facebook in any way.

\subsection{Pre- and Post-Tests}

\subsubsection{Design of the Pre- and Post-Tests}

To compare students' perceptions and experiences of Facebook before and after the online pre-master courses (sub-questions Q2, Q3, Q4, and Q5), an extended CoI survey, adapted from 
the original 34-item Likert-type scale CoI survey [16], was administered at the beginning and at the end of all six pre-master courses involved in our study. As the original 34-item CoI survey is designed to measure the three presences of the Community of Inquiry at the end of a course [16] and it is not specific for social media sites, the following three adaptations of the survey instrument used at the beginning and at the end of the course in the pre- and post-tests were necessary:

(1) Additional questions were added regarding the general use of Facebook in higher education, and regarding the effects of Facebook on students' performance (exam grades).

(2) Two extra open-ended questions were provided, in order to give students an opportunity to reflect on any possible concerns about using Facebook, or to provide any other comments regarding the use of Facebook specifically in higher education.

(3) Fifteen items of 34 in the original $\mathrm{CoI}$ instrument were excluded from the pre-test, as they specifically evaluate students' experiences of a course, and therefore are only appropriate for a post-test. The full CoI survey in its original form was used in the post-test.

Consequently, the pre-test contained 35 items, and the post-test, 55 items. The questionnaire was divided in several sections (Appendix A) according to the research questions of this study. In Table 1, an overview of the sections with the corresponding items in the questionnaire instrument is given (see complete overview Appendix A).

Table 1. Overview of the pre- and post-test items per section.

\begin{tabular}{|c|c|c|c|}
\hline $\mathbf{Q}$ & Research Question & Sections & Items \\
\hline Q2 & $\begin{array}{l}\text { How does the use of Facebook during an online course impact } \\
\text { students' perception of using Facebook for general } \\
\text { educational purposes? }\end{array}$ & 2 & $\begin{array}{l}8,9,11,12 \\
13,14\end{array}$ \\
\hline Q3 & $\begin{array}{l}\text { What effects does the use of Facebook have on students' perception } \\
\text { regarding their grades? }\end{array}$ & 2 & 10 \\
\hline Q4 & $\begin{array}{l}\text { How does the use of Facebook for teaching and learning in a course } \\
\text { influence students' perception regarding the elements of the } \\
\text { Community of Inquiry? }\end{array}$ & $3,4,5$ & $15-32$ \\
\hline Q5 & $\begin{array}{l}\text { How do students' opinions and experiences regarding the three } \\
\text { presences of the Community of Inquiry differ between the students } \\
\text { who use Facebook during their course and those who do not? }\end{array}$ & $3,4,5,6$ & $15-53$ \\
\hline
\end{tabular}

\subsubsection{Data Analysis}

The data collected by the pre- and post-test contained five-point Likert-scaled items. In order to analyze the data, first, a descriptive analysis was conducted using SPSS, version 24 . The results of the descriptive analysis are illustrated by box plot diagrams that show the distribution of the values. These graphs present the average scores, and they show boxes and lines/whiskers. The middle two quartiles of the data distribution are presented by two boxes, which represent $50 \%$ of the data. Independent samples $t$-tests were conducted to test statistically significant differences in the data obtained [37].

\section{Results}

The data were obtained from two perspectives. First the types of interactions on Facebook within an educational group were studied, and second their impacts on students' educational experiences were investigated. The types of interaction in a group were determined by conducting a transcript analysis [13]. To study the impact on students' educational experience, pre- and post-tests were taken, based on the CoI inventory [16]. The tests were conducted to investigate four points: (a) the impacts of the use of Facebook during an online course on students' perception of the use of social media (Facebook), (b) the effects of the use of Facebook on students' perceptions regarding their grades, 
(c) the changes in students' perception regarding the core elements of the Community of Inquiry as a result of using Facebook, and (d) differences in students' perception regarding the core elements of Community of Inquiry, comparing students who used Facebook during their course and those who did not.

\subsection{Qualitative Analysis Results}

\subsubsection{Facebook Open Page: “UvA Online Pre-Master Information Studies"}

A brief analysis with Facebook Insight Analytics indicated that during the period of activity of all six courses (29 May-14 July 2017), there was a clear increase in the number of views of this open Facebook page on the start date of the courses, but no posts nor comments were found on this page (Figure 1). The 36 students who in that period had access to this Facebook page and did not follow the course Academic Skills, were accordingly treated as a control group in this study.



Figure 1. Content analysis of the pre-master open Facebook page, using Grytics [34]. (Top): total views per day of the course. (Bottom): number of people who viewed the page per day of the course.

No collaborative activities were detected, such as posts and comments during the course period. 
The number of views (19) of this page were higher on the start day of the course, compared to the days before and after it.

\subsubsection{Facebook Closed Group: "Academic Skills UvA"}

The analysis of the visits of the closed group Facebook page "Academic Skills UvA" shows that contrary to the common open Facebook page of the Pre-master courses, numerous activities were found on the Facebook closed group page of the Academic Skills course (Table 2).

Table 2. Overview of activities in the Facebook closed group: "Academic Skills UvA".

\begin{tabular}{ccccc}
\hline Participant & N Posts & Posts \% & N Comments & Comments \% \\
\hline Moderator & 12 & $18 \%$ & 67 & $46 \%$ \\
Student & 55 & $82 \%$ & 79 & $54 \%$ \\
Total & 67 & $100 \%$ & 146 & $100 \%$ \\
\hline
\end{tabular}

The majority of the students $(\mathrm{N}=32,84 \%)$ in the course Academic Skills were active on Facebook, and posted on it. The majority of conversations $(\mathrm{N}=55,82 \%)$ were generated by different students. Almost half of the comments on these posts $(\mathrm{N}=67,46 \%)$ were posted by the moderator, and the rest by other students. An overview of members' engagement on Facebook, using the Grytics analytics (Figure 2) shows that the moderator had the highest scores for engagement. The names of the students and teachers are hidden on the figure for privacy reasons. Consequently, the 38 students who had access to the Facebook closed group were treated as the treatment group in this study.

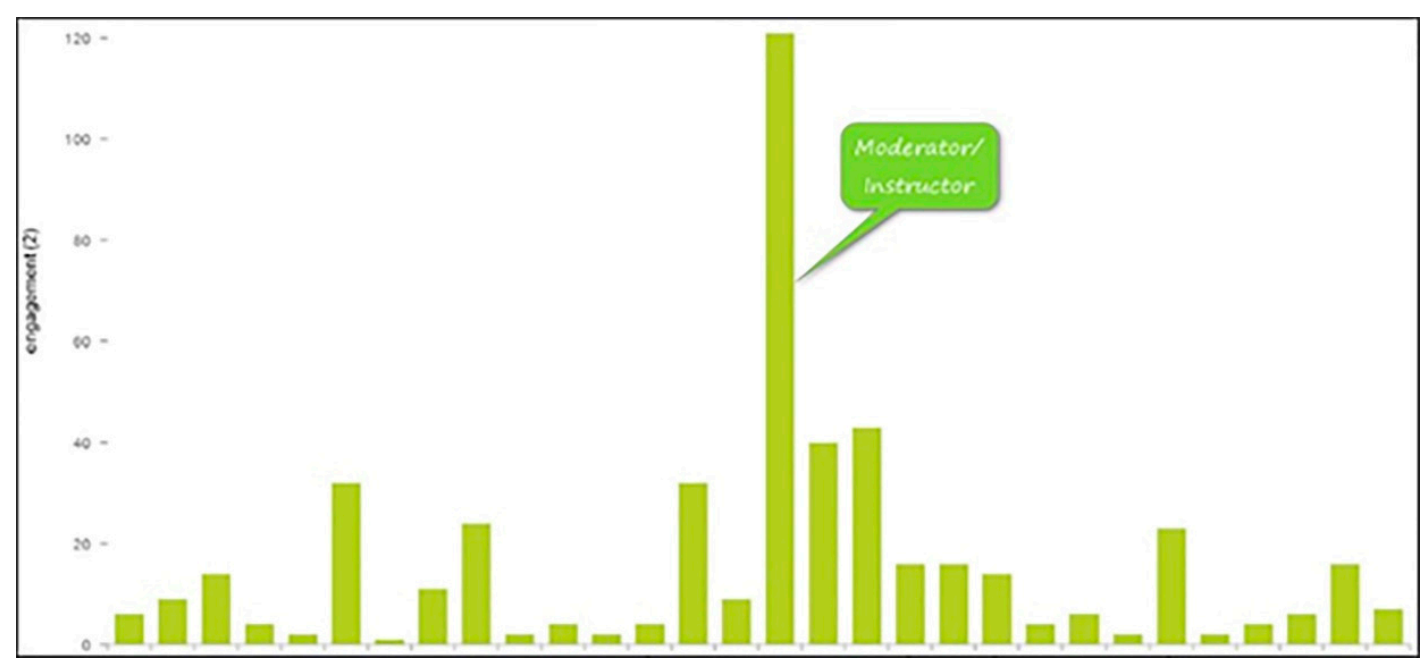

Figure 2. Member activity diagram showing the Engaged Member Score. The Engaged Members score is defined as follows: two times the number of posts posted by the member + number of comments posted by the member + number of times the member has reacted on a post (source: Grytics [34]).

The distribution of the Facebook features used for group interactions, such as posts, likes, or comments, and the types of content changed/shared on Facebook, such as status, link, video, or photo, are presented in Figure 3. The majority $(\mathrm{N}=146,62 \%)$ of total interactions $(\mathrm{N}=236,100 \%)$ were based on the comment feature. Next, posts $(\mathrm{N}=67,28 \%)$ were used, as well as likes $(\mathrm{N}=21,9 \%)$, and emoticons $(\mathrm{N}=2,1 \%)$. 


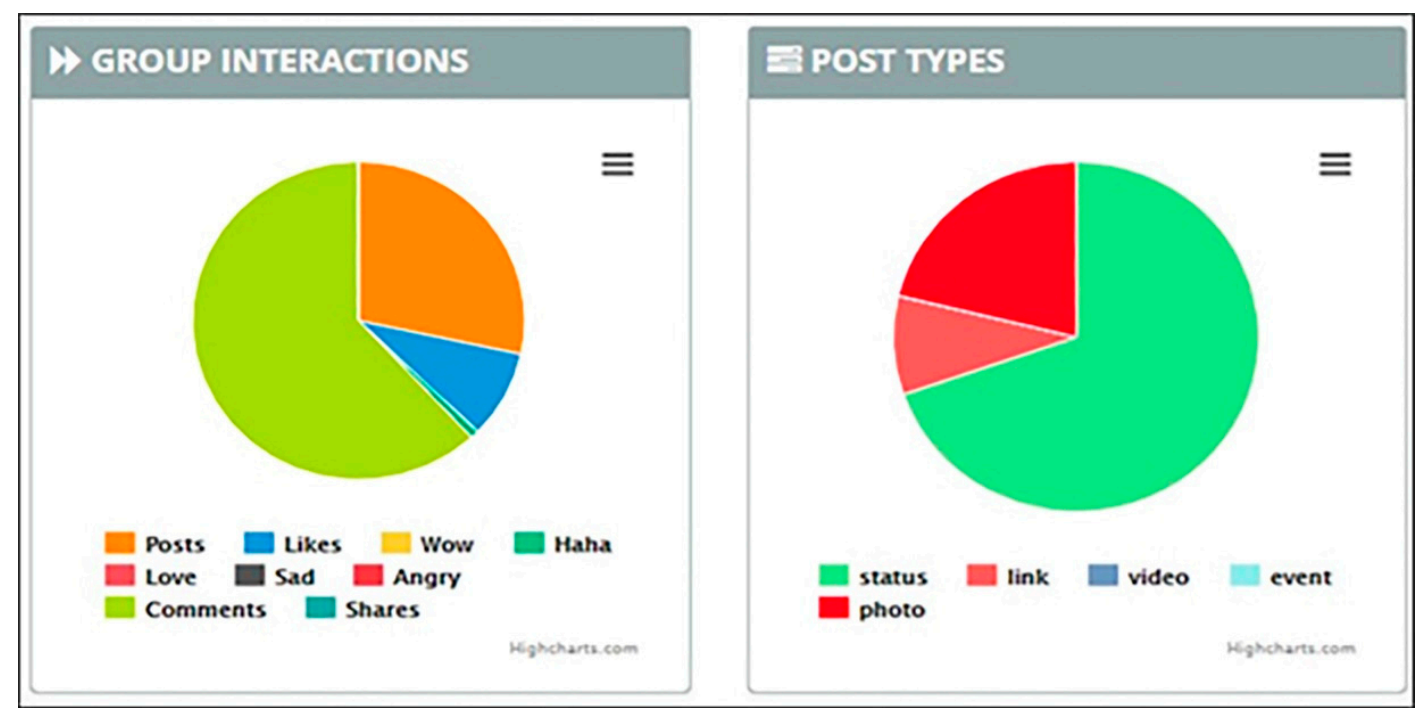

Figure 3. Group interactions and post types on the Facebook group: "Academic Skills UvA".

Using the transcript analysis method described by Akyol and Garrison [38] and CoI categories, all three types of presence according to the CoI framework, social presence, teaching presence, and cognitive presence, were recognized in the form of interactions. The same modes of interaction were defined as in the preliminary set up coding phase, where the data from the previous edition of the same course were used. The majority of the 67 posts comprised organizational, content-related, or technical issues. According to the coding scheme of the Community of Inquiry, 39 posts were organizational and technical messages, and were classified as "teaching presence" in the category 'Design \& Organization' (Table 3). Eleven posts in this category were posted by the moderator, and 29 by the students. Additionally, the moderator also posted two Group Cohesion posts. The posts of the CoI element Cognitive Presence in the categories Exploration (13) and Triggering Event (11) were only posted by students. Next to the CoI element Cognitive Presence, 15 of these posts also showed social presence.

Table 3. Community of Inquiry (CoI) categories of posts in the online course Academic Skills.

\begin{tabular}{cccc}
\hline Elements CoI & Categories & Role Author Post & No. Posts \\
\hline \multirow{2}{*}{ Social Presence } & Group Cohesion & Moderator & 2 \\
& Affective Expression & Student & 1 \\
\hline \multirow{2}{*}{ Cognitive Presence } & Exploration & Student & 13 \\
& Triggering Event & Moderator & 11 \\
\hline \multirow{2}{*}{ Teaching Presence } & Design \& Organization & Student & 29 \\
\hline
\end{tabular}

The results obtained from the transcript analysis show that three of the six interactions $[33,35]$ student-student, student-teacher and student-content are represented in the data. Both studentstudent and student-teacher interactions were found in combination with the core elements of CoI [9], i.e., social presence, teaching presence, and cognitive presence. Student-content interaction took place as a consequence of student-student (cognitive) interaction, as Blackboard was used to host the formal study material. Some students shared extra resources and additional literature, e.g., by sharing a link to a video or a relevant article. Other students then interacted with that content by, e.g., clicking on these links.

Next to messages that were clearly addressed to the moderator or to students, there were 25 (38\% of the total number) messages posted that were addressed as open to the whole community. 
We have labeled this mode of interaction the student-community interaction. Thirteen of these posts showed cognitive presence, and 12 showed teaching presence. Most of the interactions of this type were posted on the Facebook group in the form of questions. All questions were also answered this way, randomly by a student or by the moderator, to the community as a whole. The student-community mode of interaction has not been reported in the Community of Inquiry framework before. In Table 4, the types of interaction that were recognized in our study are summarized. For each of the types of observed interaction, an example of the post on the Facebook closed group is given. Due to privacy reasons, a part of the text in the examples is sometimes removed or given in brackets as a generalized expression.

Table 4. Integrated coding scheme revealed from preliminary coding phase.

\begin{tabular}{|c|c|c|}
\hline ID & Modes of Interaction & Example of the Post on Facebook \\
\hline \multirow{3}{*}{ SS } & $\begin{array}{l}\text { Student-Student Social } \\
\text { Presence, Group } \\
\text { Cohesion }\end{array}$ & $\begin{array}{l}\text { Anyone would like to study together at University Library [Name of } \\
\text { library] on Monday (5th)? }\end{array}$ \\
\hline & $\begin{array}{l}\text { Student-Student } \\
\text { Cognitive Presence, } \\
\text { Triggering Event }\end{array}$ & $\begin{array}{l}\text { Anyone would like to discuss some articles together at the end of this } \\
\text { week maybe Saturday morning around } 9 \text { ? For now i finished the } \\
\text { articles [reference given]. And try to finish at least } 2 \text { more before then. } \\
\text { Maybe } 3 \text { of } 4 \text { people is the best to discuss the articles. For me english is } \\
\text { ok or in dutch. }\end{array}$ \\
\hline & $\begin{array}{l}\text { Student-Student } \\
\text { Teaching Presence, } \\
\text { Design \& Organization }\end{array}$ & $\begin{array}{l}\text { Hi all! Today 23:59 is the deadline for the second essay. Don't forget to } \\
\text { hand it in. }\end{array}$ \\
\hline \multirow{5}{*}{ ST } & $\begin{array}{l}\text { Student-Teacher (post by } \\
\text { instructor) Social } \\
\text { Presence, Group } \\
\text { Cohesion }\end{array}$ & GOOD LUCK EVERYBODY \\
\hline & $\begin{array}{l}\text { Student-Teacher } \\
\text { Cognitive Presence, } \\
\text { Triggering Event }\end{array}$ & $\begin{array}{l}\text { Dear Instructor, I found that many articles provided by the course are } \\
\text { quite old (not from recent } 5-10 \text { years). Could you please explain the } \\
\text { reasoning behind this? Thank you. }\end{array}$ \\
\hline & $\begin{array}{l}\text { Student-Teacher (post by } \\
\text { student) Cognitive } \\
\text { Presence, Triggering } \\
\text { Event }\end{array}$ & $\begin{array}{l}\text { Hi Instructor, sorry for another question, in your powerpoint } \\
\text { presentation about confidence interval of proportion, you didn't put } \\
\text { [content explanation] Do we need to [depth of explanation] in similar } \\
\text { questions in the exam? Thanks for the explanation. }\end{array}$ \\
\hline & $\begin{array}{l}\text { Student-Teacher (post by } \\
\text { instructor) Teaching } \\
\text { Presence, Design \& } \\
\text { Organization }\end{array}$ & $\begin{array}{l}\text { some of you informed me about the students \# on the list that was send } \\
\text { recently to you. Ignore the student\#. The list was sorted without taking } \\
\text { in account the \#s. }\end{array}$ \\
\hline & $\begin{array}{l}\text { Student-Teacher (post by } \\
\text { instructor) Teaching } \\
\text { Presence, Design \& } \\
\text { Organization }\end{array}$ & $\begin{array}{l}\text { last Thursday you have received a link to a survey as part of the } \\
\text { [research] by [name of researcher]. [Name of researcher] is researching } \\
\text { the use of facebook in an academic educational environment. Please } \\
\text { note that it is very important that you complete now the } \\
\text { post-test survey. }\end{array}$ \\
\hline SC & $\begin{array}{l}\text { Student-Content (posted } \\
\text { by student to } \\
\text { community) Cognitive } \\
\text { Presence, Triggering } \\
\text { Event }\end{array}$ & $\begin{array}{l}\text { On page } 307 \text { of [Book Title] (Chapter } 9-\text { [Chapter Title]). Under the first } \\
\text { paragraph [name of Concept], ... Are we still talking about the [name of } \\
\text { concept] from the previous sub-chapter? }\end{array}$ \\
\hline
\end{tabular}


Table 4. Cont.

\begin{tabular}{|c|c|c|}
\hline ID & Modes of Interaction & Example of the Post on Facebook \\
\hline \multirow{5}{*}{$\mathrm{SCO}$} & $\begin{array}{l}\text { Student-Community } \\
\text { Social Presence, Affective } \\
\text { Expression }\end{array}$ & $\begin{array}{l}\text { Sorry this is just too funny, I have to share this with you all: Go to the } \\
\text { Glossary in online [Book Title] and look up "M and Ms". Please do, } \\
\text { laughing helps you relax. }\end{array}$ \\
\hline & $\begin{array}{l}\text { Student-Community } \\
\text { Cognitive Presence, } \\
\text { Exploration }\end{array}$ & $\begin{array}{l}\text { Hey there, I was doing the quiz of chapter } 3 \text {, I understood all questions } \\
\text { correctly except question } 7 \text {, see the print screen. The answer I gave is } \\
\text { the [name of concept]. Which are the } 8 \text { people that showed up, there is } \\
\text { no mention about how many people older than } 65 \text { live in the } \\
\text { community (Could be a small community in Antarctica for all I know). } \\
\text { So according to the text } 8 \text { people is the whole population ... }\end{array}$ \\
\hline & $\begin{array}{l}\text { Student-Community } \\
\text { Cognitive Presence, } \\
\text { Exploration }\end{array}$ & $\begin{array}{l}\text { Hey Guys, I was wondering if some of you found the same answer as i } \\
\text { did on Chapter [Title Chapter, explanation exercise]. There are two } \\
\text { groups of } 16 \text {, so ... }\end{array}$ \\
\hline & $\begin{array}{l}\text { Student-Community } \\
\text { Cognitive Presence, } \\
\text { Triggering Event }\end{array}$ & What is meant by practical setting as mentioned in assignment $2 ?$ \\
\hline & $\begin{array}{l}\text { Student-Community } \\
\text { Teaching Presence, } \\
\text { Design \& Organization }\end{array}$ & $\begin{array}{l}\text { Hi, does anyone know by any chance what the exam for [Title of the } \\
\text { Course] looks like? MCQ's or Open Q's or both? }\end{array}$ \\
\hline
\end{tabular}

\subsection{Pre- and Post-Test Results}

\subsubsection{Response to the Test and General Data about the Use of Facebook}

A total of 47 students (64\%) completed the pre- and/or post-tests. A descriptive analysis of the test results indicated that the response rate for the post-test $(\mathrm{N}=34,50 \%)$ was almost equal to the response rate of the pre-test $(\mathrm{N}=33,45 \%)$. Less than half $(\mathrm{N}=20)$ completed both the pre- and the post-tests. Accordingly, 10 respondents who have finished both tests followed Academic Skills, and only 10 in the other courses, which means that the distribution between the control group $(N=10)$ and the treatment group $(\mathrm{N}=10)$ was equal (Table 5).

Table 5. Overview of the responses per group.

\begin{tabular}{ccccc}
\hline Participants & Pre- and Post- \# & Only Pre- \# & Only Post- \# & Total \\
\hline Control group & 10 & 5 & 2 & 17 \\
Treatment group & 10 & 8 & 12 & 30 \\
Total & 20 & 13 & 14 & 47 \\
\hline
\end{tabular}

Thirty-three students filled in the pre-test. The majority $(\mathrm{N}=30,91 \%)$ already had an active Facebook account. Most of these students $(\mathrm{N}=22,67 \%)$ also indicated the use of Facebook for personal reasons, on average at least seven times per week.

In the post-test, the participants in the treatment and in the control group were asked to indicate how often, on average, they accessed the Facebook course page or group. The majority (67\%) of respondents in the control group indicated that they did not access it at all. In contrast, $95 \%$ of the respondents in the treatment group indicated that they had accessed the course Facebook group page at least once a week (Figure 4). 




Figure 4. Students' use of Facebook during the course in the treatment (right) and in control group (left) (results of the post-test).

Participants were also provided with two optional open-ended questions, in order to give them an opportunity to reflect on their additional concerns, or to provide other comments regarding the use of Facebook in higher education. The comments of students were mostly negative regarding the use of Facebook for education, showing that students were concerned about the data policy of Facebook, and about using social media as a matter of principle. However, there were also a few positive comments about the searchability of posts in Facebook, and the speed of communication. We quote three examples.

Student A (pre-test): "Personally, I have grown to dislike social media a lot. It feels too superficial and judgmental to be able to have more in-depth conversations. In addition, I feel like educational material should be treated at least a little bit confidential. I feel like if there is one company that does not treat private information in a safe way, it's Facebook".

Student B (post-test): “Using a social network should always be a choice. The way the course integrated Facebook made clear that it was not a choice at all. "Use it, or don't get involved. But don't complain if you have questions".

Student C (post-test): "It was useful for group discussions mainly, whenever any student had a question he/she would raise it up on Facebook so other students could help. I suppose that's sometimes faster than emailing the moderator and gives the students other points of view".

In the following sections, the results of the descriptive analysis are illustrated using box plot diagrams. The descriptive analysis represents the comparison of means that are perceived by both the pre- and post-tests while the data are further divided into two groups: the control group $(\mathrm{N}=10)$ and the treatment group $(\mathrm{N}=10)$.

\subsubsection{Impact on Students' Perception of the Use of Facebook in Education (Sub-Question Q2)}

A descriptive analysis was conducted based on the pre- and post-test data $(\mathrm{N}=20)$, using a Likert scale from 1 to 5 . The results in this section are presented per survey item (A: pre-test, B: post-test) using box plot diagrams (Figure 5).

The perception of students in the treatment group regarding the supportive role of Facebook next to Blackboard (statement 9, Figure 5) increased from 3.2 in the pre-test, to 3.7 in the post-test, with almost no scatter of the results, while the result in the control group remained the same (Figure 5). For all other statements, the mean scores in the control group slightly decreased in the post-test. On the other hand, in the treatment group, there was an increase on the Likert scale for all statements, except for statements 11 and 12, where a decrease from 3.9 to 3.6 for statement 11 and from 3.6 to 3.5 for statement 12 was observed. 




Figure 5. Students' perceptions of the general use of Facebook, the comparison of the pre-test (A) vs. the post-test $(\mathrm{B})$ for the treatment group $(\mathrm{N}=10)$ and the control group $(\mathrm{N}=10)$.

\subsubsection{Perception of the Use of Facebook regarding Grades}

The perception of the effect of Facebook regarding grades (sub-question Q3, Table 1) are presented in Figure 6).

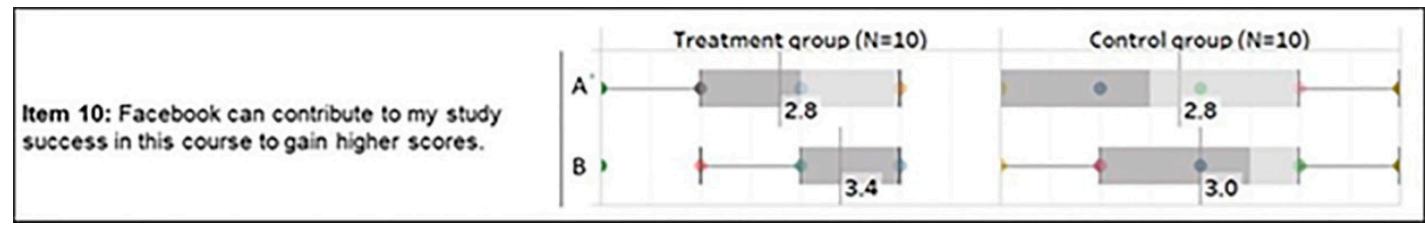

Figure 6. Difference in students' pre-test (A) and post-test (B) perceptions of the effects of Facebook on their grades.

There was an increase on the Likert's scale, observed on the post-test (Figure 6, diagrams B) in both groups; however, the increase in the treatment group was larger than in the control group. An additional analysis of only the post-test data $(\mathrm{N}=34)$ also showed also a difference in the mean scores of the two groups on survey item 10 , in the treatment group $(\mathrm{N}=22, \mathrm{M}=3.2$, diagram $\mathrm{A})$ and in the control group $(\mathrm{N}=12, \mathrm{M}=3.0$, diagram $\mathrm{B}$ ), respectively (Figure 6).

\subsubsection{Perception Regarding the Elements of the Community of Inquiry}

To find out if there was any change in perception of students about Facebook at the end of the course in comparison to the beginning of the course (sub-question Q4, Table 1) the elements of CoI were calculated and compared for the treatment and control groups for the pre- and post-tests. The results given per CoI element as mean scores on the scales obtained in the pre-test (diagrams $\mathrm{A}$ ) and the post-test (diagrams $B)$ for both the treatment $(N=10)$ and control groups $(N=10)$ are presented in Figure 7. 


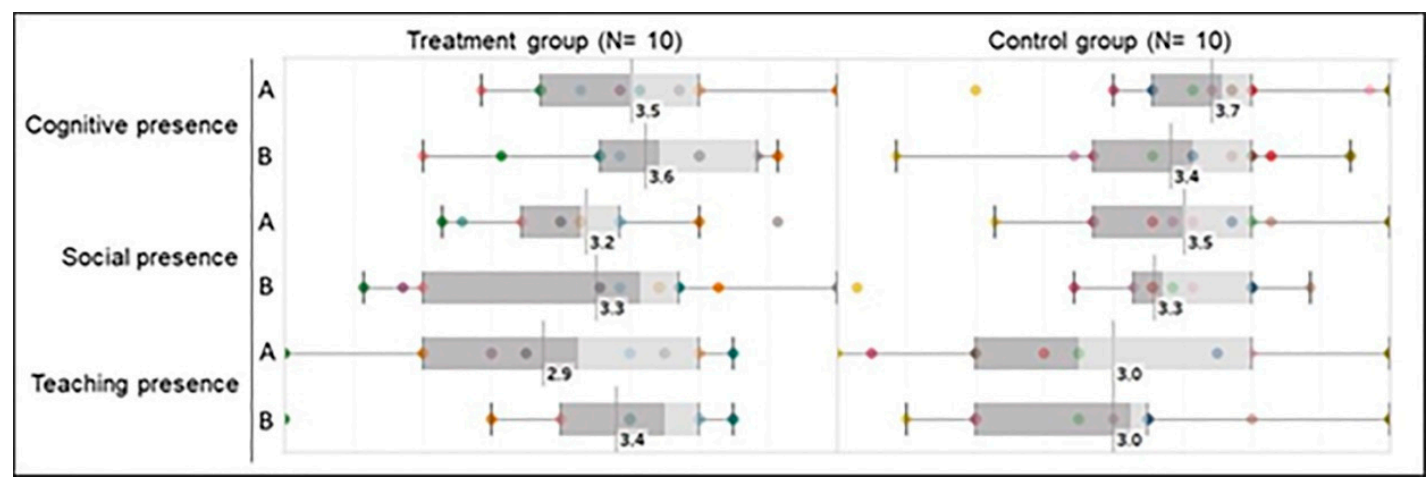

Figure 7. Difference in students' pre-test (A) and post-test (B) perceptions of the effects of Facebook on elements of the CoI.

The items about the experience with the course that were not asked in the pre-test were also not considered in the calculation of the post test. In all cases, a larger increase was observed in the treatment group in comparison to the control group. From the results (Figure 7), it can be seen that the teaching presence in the $\mathrm{CoI}$ questionnaire in the treatment group showed the largest change in the post-test, compared to the pre-test.

A descriptive analysis was also done separately, using the original set of questions of the CoI questionnaire, as the post-test contained all items of the original instrument of Garrison \& Akyol [11]. For this calculation, the data for all statements ( 34 items) of the CoI were taken into account: cognitive presence (12 items), social presence (nine items) and teaching presences (13 items), respectively. The data of all respondents $(\mathrm{N}=34)$ were used in this analysis; not only the data of the students who have completed also the pre-test. The results of this descriptive analysis (Figure 8) show that students in the treatment group perceived a relatively higher sense of all three elements of CoI, compared to those in the control group.

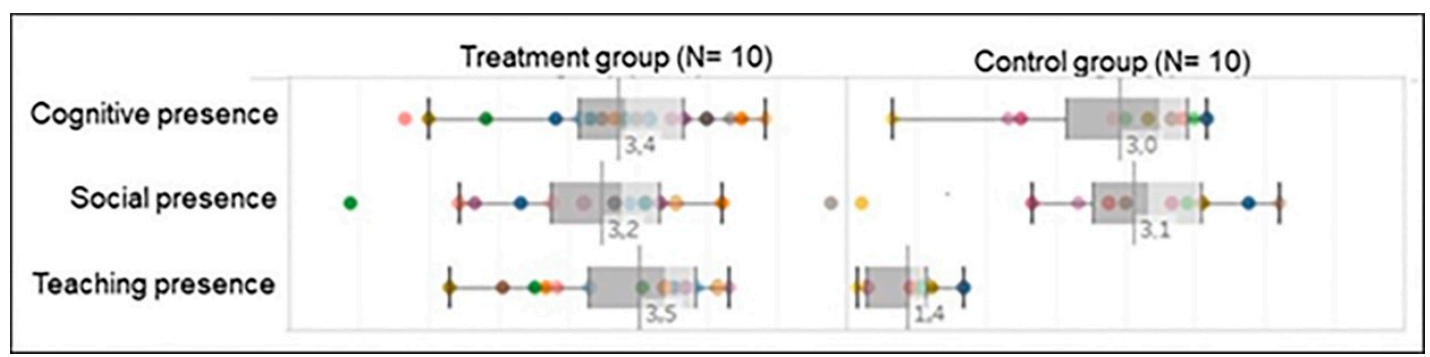

Figure 8. Difference in students' perceptions and experiences of the effects of Facebook on the elements of CoI (post-test data of all students who filled in the post-test).

\subsection{Independent Samples $t$-Tests}

Independent samples $t$-tests were conducted to estimate whether the differences between the pre- and post-tests differed statistically significantly for the treatment and control group. The results showed no significant differences between the treatment and control groups for sub-research questions Q2, Q3, and Q4. The results of the $t$-tests are presented in Tables 6-8. 
Table 6. Independent samples $t$-tests for pre- and post-test perceptions related to the question items about the general use of Facebook by students.

\begin{tabular}{|c|c|c|c|c|c|c|}
\hline Item & Question (Pre/Post) & Group & $\mathbf{N}$ & Mean df * & SD & Sig. \\
\hline \multirow{2}{*}{8} & \multirow{2}{*}{$\begin{array}{l}\text { Facebook can be used both socially, and for } \\
\text { educational purposes }\end{array}$} & Treatment & 20 & 0.1 & 0.74 & \multirow{2}{*}{0.13} \\
\hline & & Control & 10 & -0.6 & 1.17 & \\
\hline \multirow[b]{2}{*}{9} & \multirow{2}{*}{$\begin{array}{l}\text { Facebook can play a great supportive role, complementing } \\
\text { collaborative activities, next to the learning management } \\
\text { systems, such as Blackboard }\end{array}$} & Treatment & 20 & 0.5 & 0.85 & \multirow[b]{2}{*}{0.26} \\
\hline & & Control & 10 & 0 & 1.05 & \\
\hline \multirow{2}{*}{11} & \multirow{2}{*}{$\begin{array}{l}\text { Facebook is a good place to keep in contact with other } \\
\text { students from class }\end{array}$} & Treatment & 20 & -0.3 & 1.34 & \multirow[b]{2}{*}{1} \\
\hline & & Control & 10 & -0.3 & 1.49 & \\
\hline \multirow{2}{*}{12} & \multirow{2}{*}{$\begin{array}{l}\text { Facebook is a good place to discuss different topics with } \\
\text { classmates }\end{array}$} & Treatment & 20 & -0.1 & 1.37 & \multirow{2}{*}{0.27} \\
\hline & & Control & 10 & -0.8 & 1.4 & \\
\hline \multirow{2}{*}{13} & \multirow{2}{*}{ Facebook is safe to use socially } & Treatment & 20 & 0.5 & 1.18 & \multirow{2}{*}{0.19} \\
\hline & & Control & 10 & -0.1 & 0.74 & \\
\hline \multirow{2}{*}{14} & \multirow{2}{*}{ Facebook is safe to use for educational purposes } & Treatment & 20 & 0.4 & 1.26 & \multirow[b]{2}{*}{0.24} \\
\hline & & Control & 10 & -0.3 & 1.34 & \\
\hline
\end{tabular}

* Mean difference between pre- and post-tests (the pre-test is the reference).

The results of the independent sample $t$-test for question item 10 (sub-question Q3) are presented in Table 7. The result of the $t$-tests does not show significant difference between the two groups.

Table 7. Independent samples $t$-test for pre- and post-test question 10 about the perception of the effects of Facebook on the grades (question number 10).

\begin{tabular}{llccccc}
\hline \multirow{2}{*}{ Item } & \multicolumn{1}{c}{ Question (Pre/Post) } & Group & N & Mean df * & SD & Sig. \\
\hline \multirow{2}{*}{10} & Facebook can contribute to my study success in & Treatment & 20 & 0.6 & 0.84 & \multirow{2}{*}{0.25} \\
& this course to gain higher scores & Control & 10 & 0.2 & 0.63 & \\
\hline
\end{tabular}

${ }^{*}$ Mean difference between pre- and post-tests (the pre-test is the reference).

In Table 8 , the results of the independent tests for the perception of the CoI elements at the beginning and at the end of the course (sub-question Q4). No significant differences between the control and treatment group could be found.

Table 8. Independent samples $t$-test for pre- and post-test perceptions of the effects of Facebook on elements of CoI (sub-question Q4).

\begin{tabular}{cccccc}
\hline CoI elements & Group & N & Mean df & SD & Sig. \\
\hline \multirow{2}{*}{ Cognitive Presence } & Treatment & 20 & 0.1 & 0.43 & \multirow{2}{*}{0.08} \\
& Control & 10 & -0.3 & 0.51 & \\
\hline \multirow{2}{*}{ Social Presence } & Treatment & 20 & 0.07 & 0.77 & \multirow{2}{*}{0.34} \\
& Control & 10 & -0.21 & 0.5 & \\
\hline \multirow{2}{*}{ Teaching Presence } & Treatment & 20 & 0.52 & 0.73 & \multirow{2}{*}{0.1} \\
& Control & 10 & 0 & 0.6 & \\
\hline
\end{tabular}

* Mean difference between pre- and post-tests (the pre-test is the reference).

Table 9 shows independent sample $t$-test results to identify whether there was a statistically significant difference between the two groups, based only on the post-test data $(\mathrm{N}=34)$ (sub-question Q5). 
Table 9. Independent samples $t$-test effects calculated for the elements of CoI, based only on the post-test data (sub-question Q5).

\begin{tabular}{|c|c|c|c|c|c|c|}
\hline CoI Element & CoI Category & Group & $\mathbf{N}$ & Mean & SD & Sig. \\
\hline \multirow{6}{*}{ Teaching Presence } & \multirow{2}{*}{ Design and Organization } & Treatment & 22 & 3.64 & 0.77 & \multirow{2}{*}{$<0.005$} \\
\hline & & Control & 12 & 2.02 & 0.58 & \\
\hline & \multirow{2}{*}{ Facilitation } & Treatment & 22 & 3.44 & 0.59 & \multirow{2}{*}{$<0.005$} \\
\hline & & Control & 12 & 1.24 & 0.33 & \\
\hline & \multirow{2}{*}{ Direct Instruction } & Treatment & 22 & 3.52 & 0.75 & \multirow{2}{*}{$<0.005$} \\
\hline & & Control & 12 & 1.08 & 0.21 & \\
\hline \multirow{6}{*}{ Social Presence } & \multirow{2}{*}{ Affective Expression } & Treatment & 22 & 3.26 & 0.84 & \multirow{2}{*}{0.26} \\
\hline & & Control & 12 & 2.93 & 0.79 & \\
\hline & \multirow{2}{*}{ Open Communication } & Treatment & 22 & 3.17 & 0.97 & \multirow{2}{*}{0.61} \\
\hline & & Control & 12 & 3.37 & 1.17 & \\
\hline & \multirow{2}{*}{ Group Cohesion } & Treatment & 22 & 3.3 & 0.7 & \multirow{2}{*}{0.17} \\
\hline & & Control & 12 & 2.92 & 0.87 & \\
\hline \multirow{8}{*}{ Cognitive Presence } & \multirow{2}{*}{ Triggering Event } & Treatment & 22 & 3.23 & 0.89 & \multirow{2}{*}{0.07} \\
\hline & & Control & 12 & 2.64 & 0.81 & \\
\hline & \multirow{2}{*}{ Exploration } & Treatment & 22 & 3.3 & 0.84 & \multirow{2}{*}{0.27} \\
\hline & & Control & 12 & 2.97 & 0.78 & \\
\hline & \multirow{2}{*}{ Integration } & Treatment & 22 & 3.62 & 0.79 & \multirow{2}{*}{0.67} \\
\hline & & Control & 12 & 3.75 & 0.9 & \\
\hline & \multirow{2}{*}{ Resolution } & Treatment & 22 & 3.32 & 0.63 & \multirow{2}{*}{0.01} \\
\hline & & Control & 12 & 2.5 & 1.18 & \\
\hline
\end{tabular}

In Table 10, the results of the independent samples $t$-tests of the post-test for all students who filled in the post-test in the treatment and the in control group, respectively, are presented per CoI category.

Table 10. Independent samples $t$-test effects calculated for the CoI categories, based only on the post-test data (sub-question Q5).

\begin{tabular}{cccccc}
\hline CoI Elements & Group & N & Mean & SD & Sig. \\
\hline \multirow{2}{*}{ Cognitive Presence } & Treatment & 22 & 3.37 & 0.67 & \multirow{2}{*}{0.11} \\
& Control & 12 & 2.97 & 0.7 & \\
\hline \multirow{2}{*}{ Social Presence } & Treatment & 22 & 3.24 & 0.75 & \multirow{2}{*}{0.52} \\
& Control & 12 & 3.06 & 0.8 & \\
\hline \multirow{2}{*}{ Teaching Presence } & Treatment & 22 & 3.52 & 0.56 & \multirow{2}{*}{ Control } \\
& Contron & 12 & 1.42 & 0.26 & \\
\hline
\end{tabular}

A significant difference is obtained for CoI the category Teaching Presence (sub-question Q5, Table 1).

\subsection{Limitations}

There are three limitations of this research. The first limitation considering the quantitative research is related to the sample size. The size of the group sample was too small to statistically prove the differences. Consequently, we did not search for any correlations of the results with demographic data, such as age, gender, or education background as a larger sample size would be required to do this meaningfully. There is a limitation related to the sub-question Q3 (Table 1, Q3) about the effects of the use of Facebook on their grades in the pre- and post-tests. The post-test was taken before students knew their examination grades. Due to privacy reasons, comparison of the results of the post-test of this research with actual exam results was outside the scope of this research. The third limitation of 
this research relates to the fact that this study was conducted within a certain course setting. In order to be able to generalize the findings of this research, an investigation in a larger group, and also in other course settings is recommended.

\section{Discussion}

The purpose of this research was to reveal the capability of Facebook for learning in a formal learning setting and to clarify student perception of it. The qualitative transcript analysis to map out the types of interaction on the Facebook group page showed that in the treatment group, a community of inquiry was formed, indicating all three presences of the Community of Inquiry framework [9]. In the next paragraphs, we discuss this question regarding our five sub-research questions.

Q1. What types of interaction take place on Facebook within an educational group that has an impact on student educational experiences?

In our study, different types of interaction were observed. The majority of 236 interactions in total that were observed on the Facebook page of the treatment group within eight weeks of the online pre-master course Academic Skills were based on the comment feature. A total of $28 \%$ (55) of interactions were posts, and $21 \%$ were likes, while at the same time, only two emoticons were posted. In Contrary to the findings of Ractham and Firpo [39], in our case, other popular features of Facebook such as video sharing, live video streaming, and tagging were not used at all. We have observed that 29 out of 55 posts by students showed teaching presence, and that in total, only three posts on the Facebook page expressed social presence (Table 3). Garrison et al. $[9,13]$ argued that both students and teachers could show teaching presence in a CoI, explaining that all three presences are interchangeable among the members of the community, independent from their role. In our study, these basic principles of CoI were confirmed by the transcript analysis. In the cognitive domain of CoI, the interaction was classified as a triggering event, or an exploration. At the same time, the interactions student-student, student-teacher, and student-content were revealed from the data showing social presence, teaching presence, and cognitive presence. The questions and comments about the course content by students were also often addressed fully openly to the whole community and they were answered by one of the students. Several questions by students regarding the CoI element Teaching Presence, Category Design, and the organization of the course were answered by students, and not by the moderator. We propose that this could mean that a new $\mathrm{CoI}$ interaction arose, a student-community interaction that was not yet reported before in the literature. We argue that this interaction could occur in our case, because the online course design was student-centered, and because the moderator had set up a safe climate on an academic level within the whole online course, and not only on Facebook. Based on these observations, we argue that different types of interactions occurred on the Facebook page of the treatment group, which had impacts of student's education experience.

In contrast to other studies [18], among the teaching presence activity on Facebook, we did observe any direct instruction nor facilitation of discourse. We suppose that we did not observe these CoI categories, because Facebook in our case, was only one part of a complex online learning environment that was used for the online pre-master courses, and the teaching materials, assignments, and quizzes of all our online pre-master courses were available on Blackboard. Weekly online video conference meetings were organized by the moderator in all online pre-master courses on Webex, and instruction if necessary was given there. In our study, no teacher-teacher interactions, were identified, which is not surprising, as there was only one moderator in each course. We also did not observe any posts that could be classified as teacher-content or content-content interaction. This can be explained by the fact that the teaching materials were not on Facebook, but on Blackboard. On the Facebook page of the treatment group, the moderator was the most active participant (Figure 2). His activity was confirmed by the transcript analysis of the posts (Table 3). In all online pre-master courses in our programme, there was a link to the Facebook page/group on the course menu in Blackboard, but it was the decision of the students to use it or not. While in the online pre-master course Academic skills, the moderator 
was actively involved in the Facebook group, the moderators in other online pre-master courses did not interact with the Facebook page at all. On this Facebook page that was linked in Blackboard for the control group, we have observed some activity at the beginning of the courses (Figure 1), but during the whole programme, we did not observe any posts. There were a few students who were in the treatment group, and who also followed one of the other online pre-master courses at the same time. These students only posted on Facebook in the treatment group. We are convinced that in our case, posting on Facebook by students was strongly related to the activity of the moderator. These findings are in line with the core definition of teaching presence according to Anderson et al., [40] indicating that teaching presence ensures the design, facilitation, and direction of cognitive and social processes. Similarly, these results also confirm the findings of Garrison and Arbaugh, [41] and in particular their statement: "The role of moderators in cultivating cognitive presence is significant, in terms of how they structure both the course content and participant interactions." Kabilan et al. [42] stated that for a meaningful learning experience the alignment of learning outcomes with a proper integration of Facebook was necessary.

Q2. How does the use of Facebook during an online course impact students' perception of using Facebook for general educational purposes?

From the results of the pre-test in our study, it can be seen that the students in both treatment and control group had a moderately positive attitude toward the use of Facebook in education before the start of the online pre-master courses, and that there was no significant difference between the treatment and control group at that time. The post-test results indicate an increase on the Likert scale in the treatment group. The students in the treatment group were also less concerned regarding the safety of using Facebook in the post-test compared to the pre-test, while students in the control group showed slightly more concerned in the post-test than in the pre-test. In open questions, students often expressed their concerns about using Facebook for educational purposes. This is in line with other research. The potential of social media and Facebook for education is described in the literature in different articles [25]. Hickerson and Kothari [43] have pinpointed that the privacy and ethical aspects have influenced the attitudes of their students with regard to the use of social media in educational context, and they recommend for the faculties to formulate their own social media guidelines when they integrate social media into the courseware. On the other hand, in our study, in the post-test, the attitude in the treatment group in almost all cases was more positive than in the control group (Figure 5). In particular, the reaction of the students in the treatment group on item 9 (Figure 5) about the supportive role of Facebook clearly showed more positive attitudes from students in the post-test, than in the pre-test. In the treatment group, a decrease was observed (Figure 5) for statements 11 (from 3.9 to 3.6) and 12 (from 3.6 to 3.5). We assume that at the beginning of the course, the expectation about using Facebook to keep contact with classmates from all over the world was very high, and considering the results of the transcript analysis, the social interaction in the Facebook group was relatively moderate, and most interactions were related to content, or acquired organizational or technical guidance.

The findings in our study suggest that the intensive use of Facebook for educational purposes had a positive impact on the perception of using Facebook for education. However, the total sample size per group that we could compare was 10 (in both groups, only 10 students completed the pre- and post-test) and this is too small to prove any statistical significance.

Q3. What effects does the use of Facebook have on students' perception regarding their grades?

In comparison to the control group, the treatment group showed a higher post-test increase for the expectation that the use of Facebook can contribute to their study success to gain higher scores on the course (question 10, Figure 6). The group sample, however, was too small to prove this statistically. On the other hand, the qualitative transcript analysis of the Facebook data in the treatment group showed a large number of posts in the Facebook group that were closely related to the final exam. This could explain that Facebook had a positive impact on students' perception regarding their grades. 
Q4. How does the use of Facebook for teaching and learning in a course influence students' perception regarding the elements of the Community of Inquiry?

In our study, the CoI elements were calculated in the treatment and in the control group in two different ways. The first way was by comparing the pre- and post-test results on the selection of questions from $\mathrm{CoI}$ instrument, where we excluded the questions of CoI survey that were strongly related to the experiences of students during a course, because students in the pre-test would not be able to answer them before the course had started (Figure 7). The second way was by working out only the post-test data, in which the original 34-item CoI instrument was used (Figure 8). The results presented in Figure 7 show that both the treatment and control groups were slightly positive in evaluating all $\mathrm{CoI}$ elements in a general way, and that an increase in teaching presence was also observed in the treatment group.

Q5. How do students' opinions and experiences regarding the three presences of the Community of Inquiry differ between the students who use Facebook during their course and those who do not?

For students, from the treatment and the control groups who have completed the post-test data, in which the full 34-item CoI instrument was used (Figure 8), the CoI elements were determined, and they are in line with the literature results $[38,40,41,44]$. Figure 8 shows that based on the original 34-item CoI survey, considering the CoI element of Teaching Presence, after the course, there was a huge difference in the results between the treatment and the control groups in all the categories of this CoI element. These findings are supported by the results of the transcript analysis in this study, except for the category Direct Instruction, as we did not observe any posts on the Facebook group that we could categorize under Direct Instruction.

The results of the independent samples $t$-test about the opinions of students who used Facebook during their course and those who did not, showed significant differences only for Teaching Presence. The analysis revealed a significant difference between the two groups for all categories of teaching presence, including: design and organization, with a mean difference of $1.616(p<0.005)$, facilitation with a mean difference of $2.203(p<0.005)$ and direct instruction, with a mean difference of 2.439 $(p<0.005)$. The $t$-tests show no significant differences in other categories of CoI. We believe that there was also probably a statistical difference in the mean values of the two groups for some other categories, but the total sample size per group, treatment $(\mathrm{N}=22)$ and control $(\mathrm{N}=12)$, respectively, was too small to prove it by using the $t$-test calculation, as an independent $t$-test can only detect statistical differences of very large effects or very large groups.

\section{Conclusions}

The purpose of this research was to reveal the capability of Facebook for learning in a formal learning setting in higher education, in addition to a learning management system, and to clarify students' perceptions of it. The qualitative analysis using the transcript analysis method to map out the types of interaction showed that in the treatment group, a community of inquiry on Facebook was formed, having all three presences defined in the Community of Inquiry framework [9]. In particular, the interactions of student-student, student-teacher and student-content were observed. In comparison to the control group, the treatment group perceived an evidently higher sense of teaching presence, considering all its categories that were defined in the CoI framework [38]. Furthermore a new interaction that was not reported before, arose in this study. Based on the behaviors of students in our study, and the qualitative observations collected in our context, a new CoI element "student-community" interaction is suggested. More research is needed for any generalizations. We assume that this interaction in our case could occur, because the online course design was student-centered and because of strong efforts of the moderator to create a safe climate with interaction on the academic level within the whole course, and not only the activities on Facebook. In the treatment group, the use of Facebook had an impact on students' perceptions about their grades. 
With this study, we have demonstrated that a Community of Inquiry on Facebook was formed in a regular teaching and learning setting in higher education when the moderator was actively involved in the Facebook group. In online courses with similar course designs but without an active involvement of the moderator, no community of inquiry on Facebook was formed.

These results show that the use of Facebook can have positive effects on students' learning, if its use is constructively integrated in the online learning activities of a regular online course with an active learning course design. Future research is recommended, to include larger group sizes and different course designs for the regular online courses.

Author Contributions: The two authors have collaborated on this work in all stages. In conceptualization, methodology, investigation, validation the contribution of both authors M.N. and N.B. is equal. The data collection, data curation and statistical analysis was done by M.N. Writing-Original Draft preparation, review and editing was mostly done by N.B.

Funding: This research received no external funding.

Acknowledgments: We would like to thank Loek Stolwijk, the moderator of the course Academic Skills, for the access to the Facebook page and for all fruitful discussions during this research.

Conflicts of Interest: The authors declare no conflict of interest. There were no funders in this research.

\section{Appendix A. Sections and Items for the Pre- and Post-Test Questionnaires}

Section 1. Participant Information

1. Your full name:

2. Gender: 1. Female 2. Male 3. Prefer not to say.

3. Premaster course(s) you are following: (Options: Academic Skills, ICT in Organizations, Data Mining, Business Studies, Knowledge Web, Programming for Data Science).

4. What is your current location?

5. Do you have a Facebook account?

Yes

6. How often, on average, do you access Facebook per week?

A. 1-3 $\times$ a week B. $4-6 \times$ a week C. 7 or more $\times$ a week

No

7. If you don't have a Facebook account, are you prepared to create it in order to participate in course activities on Facebook?

Please choose the answer that best reflects your view for each item. Answer each item as truthfully as possible using the following rating scale.

5 point Likert-type scale

$1=$ strongly disagree, 2 = disagree, $3=$ neutral, $4=$ agree, $5=$ strongly agree

\section{Section 2. General Questions}

8. Facebook can be used both socially and for educational purposes.

9. Facebook can play a great supportive role, complementing collaborative activities, next to the learning management systems such as Blackboard.

10. Facebook can contribute to my study success in this course to gain higher scores.

11. Facebook is a good place to keep in contact with other students from class.

12. Facebook is a good place to discuss different topics with classmates.

13. Facebook is safe to use socially.

14. Facebook is safe to use for educational purposes. 
Section 3. Teaching Presence

Design \& Organization

15. A moderator/teacher can communicate important course topics on Facebook

16. A moderator/teacher can communicate important course goals on Facebook

\section{Facilitation}

17. A moderator/teacher can facilitate learning on Facebook.

\section{Direct Instruction}

18. A moderator/teacher can give instruction and feedback on Facebook.

\section{Section 4. Social Presence}

\section{Affective Expression}

19. Getting to know other course participants gives me a sense of belonging in the course.

20. Online or web-based communication is an excellent medium for social interaction.

\section{Open Communication}

21. I feel comfortable conversing through Facebook.

22. I feel comfortable participating in the course discussions on Facebook.

23. I feel comfortable interacting with other course participants on Facebook.

\section{Group Cohesion/Communication}

24. Online discussions help me to develop a sense of collaboration.

25. I feel comfortable to communicate within a group on Facebook.

\section{Section 5. Cognitive Presence}

\section{Triggering Event}

26. Problems posed on Facebook can increase my interest in course issues.

27. Exploring content related questions on Facebook, can increase my motivation.

\section{Exploration}

28. Online discussions are valuable in helping me appreciate different perspectives.

29. Utilizing information online and discussions about it on Facebook can improve my understanding of fundamental concepts of the course I'm following.

Integration

30. Combining new information help me answer questions raised in course activities.

31. Learning activities help me construct explanations/solutions.

32. Reflection on course content and discussions help me understand fundamental concepts in courses that I follow.

\section{Section 6. Extra Post-Evaluation Questions}

33. One or more of my moderators/teachers stimulated the use of Facebook. 
34. How often, on average, did you access your course Facebook page or group?

(Options: A. $0 \times$ a week, B. 1-3× a week, C. $4-6 \times$ a week or D. 7 or more $\times$ a week)

35. Which other tools did your moderator/teacher encouraged you to use for collaboration purposes next to the Blackboard?

(options: A. Facebook, B: Other social network sites, C: WebEx, D: others ...)

36. The moderator/teacher clearly communicated important due dates/time frames for learning activities on Facebook.

37. Course activities on Facebook piqued my curiosity.

38. The moderator/teacher was helpful in identifying areas of agreement and disagreement on course topics that helped me to learn on Facebook.

39. I felt that my point of view was acknowledged by other course participants on Facebook.

40. The moderator/teacher helped to keep course participants engaged and participating in productive dialogue on Facebook.

41. I can describe ways to test and apply the knowledge created in this course on Facebook.

42. The moderator/teacher encouraged course participants to explore new concepts in this course on Facebook.

43. Brainstorming and finding relevant information on Facebook helped me resolve content related questions.

44. The moderator/teacher actions reinforced the development of a sense of community among course participants on Facebook.

45. The moderator/teacher helped to focus discussion on relevant issues in a way that helped me to learn on Facebook.

46. The moderator/teacher provided feedback that helped me understand my strengths and weaknesses relative to the course's goals and objectives on Facebook.

47. The moderator/teacher provided feedback in a timely fashion on Facebook.

48. I was able to form distinct impressions of some course participants on Facebook.

49. The moderator/teacher provided clear instructions on how to participate in course learning activities on Facebook.

50. I have developed solutions to course problems that can be applied in practice.

51. The moderator/teacher helped keep the course participants on task in a way that helped me to learn on Facebook.

52. I can apply the knowledge created in this course to my work or other non-class related activities.

53. The moderator/teacher was helpful in guiding the class towards understanding course topics in a way that helped me clarify my thinking on Facebook.

\section{Open Question}

54. If you have any other comments, regarding the effects of the use of social media in higher education, please provide it here.

55. If you have any other comments, regarding how you used Facebook or any other tool during your premaster course(s) which improved your learning outcomes, please provide it here.

\section{References}

1. Ellison, N.B.; Steinfield, C.; Lampe, C. The Benefits of Facebook "Friends:" Social Capital and College Students' Use of Online Social Network Sites. J. Comput.-Med. Commun. 2007, 12, 1143-1168. [CrossRef]

2. Manca, S.; Ranieri, M. Is it a tool suitable for learning? A critical review of the literature on Facebook as a technology-enhanced learning environment. J. Comput.-Assist. Learn. 2013, 29, 487-504. [CrossRef] 
3. Manca, S.; Ranieri, M. Facebook and Others. Potentials and obstacles of social media for teaching in higher education. Comput. Educ. 2016, 95, 216-230. [CrossRef]

4. Doleck, T.; Lajoie, S. Social networking and academic performance: A review. Educ. Inf. Technol. 2018, 23, 435-465. [CrossRef]

5. Aydin, S. A review of research on Facebook as an educational environment. Educ. Tech. Research. Dev. 2012, 60, 1093-1106. [CrossRef]

6. Freeman, S.; Eddy, S.L.; McDonough, M.; Smith, M.K.; Okoroafor, N.; Jordt, H.; Wenderoth, M.P. Active learning increases student performance in science, engineering, and mathematics. Proc. Natl. Acad. Sci. USA 2014, 111, 8319-8320. [CrossRef] [PubMed]

7. Chiu, P.H.P.; Cheng, S.H. Effects of active learning classrooms on student learning: A two year empirical investigation on student perceptions and academic performance. Higher Educ. Res. Dev. 2017, 36, 269-279. [CrossRef]

8. Chen, B.; deNoyelles, A.; Zydney, J.; Patton, K. Creating a Community of Inquiry in large-enrollment online courses: An exploratory study on the effect of protocols within online discussions. Online Learn. 2017, 21, 165-188. [CrossRef]

9. Garrison, D.R.; Anderson, T.; Archer, W. Critical inquiry in a text-based environment: Computer conferencing in higher education. Internet Higher Educ. 2000, 2, 87-105. [CrossRef]

10. Garrison, D.R.; Anderson, T.; Archer, W. The first decade of the community of inquiry framework: A retrospective. Internet Higher Educ. 2010, 13, 5-9. [CrossRef]

11. Garrison, D.R.; Akyol, Z. Toward the development of a metacognition construct for communities of inquiry. Internet Higher Educ. 2013, 17, 84-89. [CrossRef]

12. Garrison, D.R. E-Learning in the 21st Century: A Community of Inquiry Framework for Research and Practice; Routledge: New York, NY, USA, 2016.

13. Garrison, D.R.; Cleveland-Innes, M.; Koole, M.; Kappelman, J. Revisiting methodological issues in the analysis of transcripts: Negotiated coding and reliability. Internet Higher Educ. 2006, 9, 1-8. [CrossRef]

14. Arbaugh, J.B. An empirical verification of the community of inquiry framework. J. Asynchronous Learn. Netw. 2007, 11, 73-85.

15. Parker, J.; Herrington, J. Setting the climate in an authentic online community of learning. In Australian Association for Research in Education (AARE) 2015; Notre Dame University: Fremantle, Australia, 2015.

16. Arbaugh, J.B.; Cleveland-Innes, M.; Diaz, S.R.; Garrison, D.R.; Ice, P.; Richardson, J.C.; Swan, K.P. Developing a Community of Inquiry instrument: Testing a measure of the Community of Inquiry framework using a multi-institutional sample. Internet Higher Educ. 2008, 11, 133-136. [CrossRef]

17. Swan, K.; Richardson, J.C.; Ice, P.; Garrison, D.R.; Cleveland-Innes, M.; Arbaugh, J.B. Validating a measurement tool of presence in online communities of inquiry. E-mentor 2008, 2. Available online: http:/ / www.e-mentor.edu.pl/artykul/index/numer/24/id/543 (accessed on 3 January 2019).

18. Kozan, K.; Richardson, J.C. New Exploratory and Confirmatory Factor Analysis Insights into the Community of Inquiry Survey. Internet Higher Educ. 2014, 23, 39-47. [CrossRef]

19. Resta, P.; Laferrière, T. Technology in support of collaborative learning. Educ. Psychol. Rev. 2007, 19, 65-83. [CrossRef]

20. Harasim, L. Learning Theory and Online Technologies; Routledge: New York, NY, USA; London, UK, 2012.

21. Kim, K.; Sharma, P.; Land, S.; Furlong, K. Effects of Active Learning on Enhancing Student Critical Thinking in an Undergraduate General Science Course. Innov. Higher Educ. 2013, 38, 223-235. [CrossRef]

22. Rutledge, M.L.; Bonner, J.W.; Lampley, S.A. The impact of active-learning exercises on the grade distribution in a large lecture, general education biology course. J. Coll. Sci. Teach. 2015, 44, 16-25. [CrossRef]

23. Szeto, E. Community of Inquiry as an instructional approach: What effects of teaching, social and cognitive presences are there in blended synchronous learning and teaching? Comput. Educ. 2015, 81, 191-201. [CrossRef]

24. Klamma, R.; Chatti, M.A.; Duval, E.; Hummel, H.; Hvannberg, E.H.; Kravcik, M.; Law, E.; Naeve, A.; Scott, P. Social software for life-long learning. J. Educ. Technol. Soc. 2007, 10, 72-83.

25. Tess, P.A. The role of social media in higher education classes (real and virtual): A literature review. Comput. Hum. Behav. 2013, 29, A60-A68. [CrossRef] 
26. Selwyn, N. The Europa world of learning 2012. In Social Media in Higher Education; Gladman, A., Ed.; Routledge: London, UK, 2011; pp. 1-9. Available online: www.worldoflearning.com (accessed on 3 January 2019).

27. McCarthy, J. Blended learning environments: Using social networking sites to enhance the first year experience. Aust. J. Educ. Technol. 2010, 26, 729-740. [CrossRef]

28. Irwin, C.; Ball, L.; Desbrow, B.; Leveritt, M. Students' perceptions of using Facebook as an interactive learning resource at university. Aust. J. Educ. Technol. 2012, 28, 1221-1232. [CrossRef]

29. Sanchez, R.A.; Cortijo, V.; Javed, U. Students' perceptions of Facebook for academic purposes. Comput. Educ. 2014, 70, 138-149. [CrossRef]

30. Sharma, S.K.; Joshi, A.; Sharma, H. A multi-analytical approach to predict the Facebook usage in higher education. Comput. Hum. Behav. 2016, 55, 340-353. [CrossRef]

31. Mazman, S.G.; Usluel, Y.K. Modeling educational use of Facebook. Comput. Educ. 2010, 55, 444-453. [CrossRef]

32. Hew, K.F. Students' and teachers' use of Facebook. Comput. Hum. Behav. 2011, 27, 662-676. [CrossRef]

33. Garrison, D.R.; Anderson, T. E-learning in the 21st Century: A Framework for Research and Practice; Routledge/Falmer: London, UK, 2003.

34. Grytics. Available online: www.grytics.com (accessed on 2 January 2019).

35. Anderson, T.; Garrison, D.R. Learning in a networked world: New roles and responsibilities. In Distance Learners in Higher Education; Gibson, C., Ed.; Atwood: Madison, Wi, USA, 1998; pp. 97-112.

36. Garcia, A.C.; Standlee, A.I.; Bechkoff, J.; Cui, Y. Ethnographic Approaches to the Internet and Computer-Mediated Communication. J. Contemp. Ethnogr. 2009, 38, 52-84. [CrossRef]

37. De Winter, J.C.F.; Dodou, D. Five-Point Likert Items: T Test versus Mann-Whitney-Wilcoxon. Practical Assessment. Res. Eval. 2010, 15, 1-12.

38. Akyol, Z.; Garrison, D.R. The Development of a Community of Inquiry over Time in an Online Course: Understanding the Progression and Integration of Social, Cognitive and Teaching Presence. J. Asynchronous Learn. Netw. 2008, 12, 3-22.

39. Ractham, P.; Firpo, D. Using Social Networking Technology to Enhance Learning in Higher Education: A Case Study Using Facebook. System Sciences (HICSS). In Proceedings of the 2011 44th Hawaii International Conference on System Sciences, Kauai, HI, USA, 4-7 January 2011; pp. 1-10. [CrossRef]

40. Anderson, T.; Rourke, L.; Garrison, D.R.; Archer, W. Assessing teaching presence in a computer conference context. J. Asynchronous Learn. Netw. 2001, 5, 1-17.

41. Garrison, D.R.; Arbaugh, J.B. Researching the community of inquiry framework: Review, issues, and future directions. Internet Higher Educ. 2007, 10, 157-172. [CrossRef]

42. Kabilan, M.K.; Ahmad, N.; Abidin, M.J.Z. Facebook: An online environment for learning of English in institutions of higher education? Internet Higher Educ. 2010, 13, 179-187. [CrossRef]

43. Hickerson, A.; Kothari, A. Learning in Public: Faculty and Student Opinions about Social Media in the Classroom. J. Mass Commun. Educ. 2017, 72, 397-409. [CrossRef]

44. Cho, M.-H.; Tobias, S. Should Instructors Require Discussion in Online Courses? Effects of Online Discussion on Community of Inquiry, Learner Time, Satisfaction, and Achievement. Int. Rev. Res. Open Distrib. Learn. 2016, 17, 123-140. [CrossRef]

(C) 2019 by the authors. Licensee MDPI, Basel, Switzerland. This article is an open access article distributed under the terms and conditions of the Creative Commons Attribution (CC BY) license (http://creativecommons.org/licenses/by/4.0/). 